\title{
Pengaruh Pemberian Pendidikan Memandikan Bayi pada Ibu Primigravida terhadap Pengetahuan Memandikan Bayi Usia 0-7 Hari
}

Effect of Education to Bathe a Baby on Primigravida Mother to Baby Knowledge of Bathing Age 0-7 Days

\author{
Kicki Nurul Waqit Dea*, Halimatus Saidah, Siswi Wulandari \\ *Program Studi IImu Kebidanan D.IV, Fakultas IImu Kesehatan, Universitas Kadiri \\ Kediri \\ JL, Selomangleng No. 1 Kediri, Telp.(0354)775074/771846 \\ Email: *nurulkicki30@gmail.com
}

\begin{abstract}
ABSTRAK
Memandikan bayi dengan benar merupakan suatu pengetahuan yang harus dimiliki seorang ibu dalam merawat bayi. Permasalahan di masyarakat banyak ibu hamil khususnya primigravida belum mengetahui cara memandikan bayi yang benar. Solusi untuk meningkatkan pengetahuan memandikan bayi adalah diberi pendidikan tentang memandikan bayi. Tujuan penelitian ini adalah untuk mengetahui pengaruh pemberian pendidikan memandikan bayi pada ibu primigravida terhadap pengetahuan memandikan bayi usia 0-7 hari. Metode penelitian yang digunakan yaitu Pre-eksperiment dengan dengan menggunkan model One Group PretestPostets Desain. Teknik Pengambilan Sampel yaitu total sampling dengan jumlah 17 sampel. Pengolahan data menggunakan uji wilcoxon signed rank test dengan dengan taraf signifikasi (a)0,05. Hasil penelitian menunjukan sebelum diberika Pendidikan 29,4\% memiliki pengetahuan baik, 47,1\% memiliki pengetahuan cukup dan $23,5 \%$ memiliki pengetahuan kurang. Setelah diberikan pendidikan menunjukan $88,2 \%$ memiliki pengetahuan baik, $0 \%$ memiliki pengetahuan cukup dan $11,8 \%$ memiliki pengetahuan kurang. Hasil uji Wilcoxon signed rank didapatkan $\rho=0,003<$ 0,05 berarti berarti ada pengaruh pendidikan tentang memandikan bayi terhadap pengetahuan pada ibu primigravida. Semakin baik pengetahuan ibu dalam memandikan bayi maka akan memunculkan kesadaran ibu untuk memandikan bayi dengan benar. Diharapkan tenaga kesehatan memberikan pendidikan tentang memandikan bayi pada ibu primigravida untuk meningkatkan pengetahuan baik pada kelas ibu hamil maupun pada kegiatan yang lain.
\end{abstract}

Kata Kunci: Primigravida, Pendidikan memandikan bayi, pengetahuan memandikan bayi 


\begin{abstract}
Bathing a baby properly is a knowledge that a mother must have in caring for a baby. The problem in society is that many pregnant women, especially primigravidas, do not know how to bathe their babies properly. The solution to increase knowledge about bathing babies is to be given education about bathing babies. The purpose of this study was to determine the effect of bathing education for primigravida mothers on bathing knowledge of infants aged 0-7 days. The research method used is pre-experiment by using the One Group Pretest-Postets Design model. Sampling technique is total sampling with a total of 17 samples. Data processing used the Wilcoxon signed rank test with a significance level (a) of 0.05 . The results showed that before education, 29.4\% had good knowledge, $47.1 \%$ had sufficient knowledge and $23.5 \%$ had less knowledge. After being given education, it shows that $88.2 \%$ have good knowledge, $0 \%$ have sufficient knowledge and $11.8 \%$ have less knowledge. The Wilcoxon signed rank test results obtained $\rho=0.003$ $<0.05$, which means that there is an effect of education about bathing babies on knowledge of primigravida mothers. The better the mother's knowledge in bathing the baby, the better the mother's awareness will be to bathe the baby properly. It is hoped that health workers will provide education about bathing babies to primigravida mothers to increase knowledge both in the class of pregnant women and in other activities.
\end{abstract}

Keywords : Primigravida, Education to bathe infants, knowledge of bathing infants

\title{
PENDAHULUAN
}

Memandikan bayi adalah suatu cara membersihkan tubuh bayi dengan air dengan cara menyiram, merendam diri dalam air berdasarkan urutan yang sesuai (Impartina, 2016). Tujuan dari memandikan bayi yaitu untuk memberikan rasa nyaman, memperlancar sirkulasi darah, mencegah infeksi, meningkatkan daya tahan tubuh, menjaga dan merawat integritas kulit (Walsh, 2014). Selain itu memandikan bayi juga sebagai alat komunikasi antara orang tua dengan bayi, karena saat mandi biasanya orang tua melakukan sentuhan, usapan dan bicara langsung walaupun bayi tidak tidak mengerti arti ucapan tersebut.

Memandikan bayi dengan benar merupakan suatu pengetahuan yang harus dimiliki seorang ibu dalam merawat bayi. Permasalahan yang terjadi di masyarakat banyak ibu khususnya ibu yang baru pertama kali hamil (primigravida) belum mengetahui bagaimana cara memandikan bayi yang benar. Menjadi ibu baru memang tak mudah, dibutuhkan ekstra hati-hati serta persiapan yang benar agar memandikan bayi tak hanya berjalan lancar namun juga menyenangkan bagi mereka (Hidayah, 2015). Memandikan bayi memiliki tantangan tersendiri bagi orang tua terumata bila mereka baru pertama kali mempunyai seorang bayi. Tidak sedikit 
dari mereka yang tidak tahu bagaimana cara memandikan bayi sehingga mereka menyerahkan bayinya kepada pengasuh atau neneknya (Alawiyah, 2018).

Penelitian yang dilakukan Rustini dkk (2015) dibeberapa wilayah Indonesia, di peroleh data bahwa bayi yang di mandikan oleh dukun sebesar $78.5 \%$, sedangkan yang dimandikan oleh keluarga yaitu neneknya sebesar 2,5\%. Hal ini menunjukkan sedikit peran ibu atau keluarga dalam perawatan bayi sehari-hari (Impartina, 2016). Hasil penelitian Hidayah (2015) didapatkan ibu dengan pengetahuan cukup tentang cara memandikan bayi sebanyak 33 orang yaitu $52 \%$, ibu dengan sikap negatif (tidak mendukung) tentang cara memandikan bayi sebanyak 37 orang yaitu 59\%. Hasil penelitian Cahyono (2019) menunjukkan bahwa tingkat pengetahuan responden pada pretest yaitu pengetahuan cukup sebanyak 11 orang (61,1\%), berpengetahuan baik sebanyak 6 orang $(33,3 \%)$ dan berpengetahuan kurang 1 orang $(5,6 \%)$. Selanjutnya pada posttest setelah dilakukan pendidikan kesehatan pengetahuan ibu hamil mengalami peningkatan dengan pengetahuan baik sebanyak 13 orang $(72,2 \%)$ dan yang berpengetahuan cukup 5 orang $(27,8 \%)$.

Berdasarkan studi pendahuluan di Puskesmas Pesantren 1 Kota Kediri tahun 2020 terhadap 6 ibu hamil primigravida, di ketahui 4 orang (70\%) mengatakan belum pernah mendapatkan informasi tentang memandikan bayi dan belum mempunyai pengetahuan. Sedangkan 2 orang (30\%) mengatakan sudah mendapatkan informasi memandikan bayi, yang satu mendapatkan informasi melalui internet dan yang satunya lagi mendapatkan informasi melalui saudaranya yang mempunyai bayi. Berdasarkan kenyataan di atas menunjukkan bahwa masih banyak ibu primigravida belum mendapatkan informasi tentang memandikan bayi dan tidak memiliki pengetahuan dalam memandikan bayi.

Beberapa faktor yang mempengaruhi pengetahuan ibu dalam memandikan bayi di pengaruhi oleh dua faktor yaitu: faktor internal (Umur, pendidikan, pekerjaan), dan faktor eksternal ( informasi, lingkungan, dan sosial budaya) (Notoatmodjo, 2014). Sedangkan faktor lain menurut Rohmana dan Tat (2018) yaitu faktor pengalaman yang didapat dari apa yang pernah dialami sendiri maupun pengalaman orang lain yang yang diketahuinya.

Dampak dari kurangnya pengetahuan ibu dalam memandikan bayi yaitu akan mengakibatkan kurangnya bounding atau jalinan kasih antara ibu dan bayi dan media komunikasi antara orang tua, terutama ibu dengan bayi (Impartina, 2016). Namun memandikan bayi yang berlebihan dapat mengarah pada kondisi hipotermi dan sangat membahayakan keselamatan bayi. Selain menyebabkan ketidak nyamanan, mandi berlebih dapat menyebabkan dermatitis popok dan memperburuk cradle cap, oleh karena itu di perlukannya pengetahuan agar tidak terjadi kesalahan dalam memandikan bayi (Walsh, 2014).

Primigravida adalah wanita yang mengalami pengalaman pertama kehamilan atau hamil pertama, Kelahiran anak pertama merupakan situasi krisis bagi seorang 
wanita karena mengalami perubahan peran dan pola hidup dalam dirinya. Krisis yang terjadi pada ibu primigravida biasanya dipengaruhi oleh kurangnya pengetahuan ibu dalam melakukan perawatan bayi setelah lahir yaitu salah satunya adalah memandikan bayi (Sugiyanto \& Prasetyo, 2018). Ibu yang belum mempunyai Pengetahuan memandikan bayi berarti belum mampu memandikan bayi sesuai aturan dan bisa terjadi kesalahan dalam merawat bayi (Hidayah, 2015).

Solusi untuk meningkatkan pengetahuan memandikan bayi adalah ibu hamil diberi pendidikan yang cukup tentang memandikan bayi, sehingga dapat memandikan bayi secara optimal (Pepi Hapitria, 2017). Kunjungan profesional kesehatan masyarakat untuk memberikan pendidikan adalah penentu penting atas pengetahuan mengenai bayi baru lahir yaitu memandikan bayi (Best et al., 2019). Pemberian pengetahuan memandikan bayi dapat dilakukan dengan mengadakan pendidikan pada ibu hamil, Serta memberikan leaflet tentang memandikan bayi. Upaya tersebut dilakukan agar ibu yang mempunyai bayi khususnya ibu primigravida mempunyai pengetahuan memandikan bayi dan memunculkan kesadaran ibu untuk memandikan bayi dengan benar.

Berdasarkan latar belakang di atas, peneliti tertarik untuk melakukan penelitian dengan judul "pengaruh pemberian pendidikan memandikan bayi pada ibu primigravida terhadap pengetahuan memandikan bayi usia 0-7 hari di wilayah kerja Puskesmas Pesantren 1 Kota Kediri tahun 2020".

\section{METODE}

Metode penelitian dalam penelitian ini adalah eksperimen. Rancangan penelitian yang digunakan pre-eksperiment dengan menggunkan model One Group Pretest-Postets Desain. Berdasarkan cara pengumpulan data termasuk jenis penelitian observasi yang dilakukan dua kali yaitu sebelum pendidikan, yang disebut pretest $(\mathrm{O} 1)$ dan setelah pendidikan disebut post test $(\mathrm{O} 2)$, sumber data termasuk rancangan penelitian primer.

Populasi dalam penelitian ini adalah semua ibu primigravida diwilayah kerja Puskesmas Pesantren1, Kota Kediri Tahun 2020, sejumlah 17 Responden. Sampel dalam penelitian ini adalah semua ibu primigravida yang sudah bersedia menjadi responden, yaitu sebanyak 17 ibu primigravida di Wilayah kerja Puskesmas Pesantren 1, Kota Kediri tahun 2020. teknik pengambilan sampelnya menggunakan teknik total sampling. Dimana setiap ibu primigravida dalam populasi menjadi sampel dalam penelitian.

Pada penelitian ini Instrumen yang digunakan adalah lembar observasi yang berupa Kuesioner menggunakan google from. Karena penelitian di lakukan pada saat pandemi COVID-19 dimana penerapan jarak social, penggunaan teknik pengumpulan data secara jarak jauh menjadi keharusan untuk efesiensi waktu, biaya, dan keamanan, sehingga peneliti membuat whatApp Group untuk penelitian 
secara online yaitu mengisi kuesioner sebelum pendidikan selama 15 menit, kemudian diberikan pendidikan memandikan bayi melalui power point dan Leaflet yang dikirim ke whatsapp selama 50 menit, Setelah itu responden diberi waktu 15 menit untuk mengisi kuesioner sesudah diberikan pendidikan yang dikirim ke group penelitian.

Uji statistik yang digunakan dalam analisis data penelitian ini adalah wilcoxon signed rank test.

\section{HASIL DAN PEMBAHASAN}

Tabel 1 Pengetahuan ibu primigravida sebelum diberikan pendidikan memandikan bayi

\begin{tabular}{clcc}
\hline No. & Kriteria & Frekuensi (f) & Prosentase (\%) \\
\hline 1. & Baik & 5 & 29.4 \\
2. & Cukup & 8 & 47.1 \\
3. & Kurang & 4 & 23.5 \\
\hline & Jumlah & 17 & 100 \\
\hline
\end{tabular}

Tabel 1 menunjukkan hampir setengahnya ibu primigravida yaitu sebanyak 8 $(47,1 \%)$ sebelum diberikan Pendidikan memandikan bayi memiliki pengetahuan cukup, ibu primigravida berpengetahuan baik yaitu $5(29,4 \%)$, dan $4(23,5 \%)$ ibu primigravida berpengetahuan kurang.

Pengetahuan mempunyai 6 perilaku yaitu tahu, Memahami, aplikasi, analisis, sintesis dan evaluasi.Perilaku yang didasari oleh pengetahuan akan lebih langgeng dari pada perilaku yang tidak didasari oleh pengetahuan (Notoatmodjo, 2014). Hasil penelitian ini menunjukkan bahwa ibu primigravida dengan pengetahuan yang cukup berada di tingkat pengetahuan tahu saja, yang diartikan belum paham secara mendalam serta belum diaplikasikan dalam kehidupan sehari-hari apa yang di ketahui tersebut.

Hampir setengah ibu primigravida berpengetahuan cukup dikarenakan faktor umur ibu. Menurut Elizabeth B (2015) umur adalah usia individu yang terhitung mulai saat dilahirkan sampai saat berulang tahun. Semakin cukup umur, tingkat kematangan dan kekuatan seseorang akan lebih matang dalam berfikir dan bekerja. Hasil peneliti menunjukkan Ibu primigravida yang berumur 20-35 tahun memiliki tingkat pengetahuan yang cukup, dikarena kurangnya pemahaman secara mendalam dan kurangnya pengalaman dalam memandikan bayi maka hanya berpengetahuan cukup saja dalam memandikan bayi.

Kemudian ibu primigravida berpengetahuan cukup dikarenakan faktor pendidikan terakhir. Menurut Notoatmodjo (2012), semakin tinggi pendidikan seseorang akan cenderung mendapatkan banyak informasi, baik dari orang lain maupun media massa. Semakin banyak informasi yang masuk semakin banyak pula pengetahuan yang di dapat tentang kesehatan. Hasil penelitian menunjukkan 
jenjang pendidikan menegah yang dimana seseorang dengan lulusan SMA memiliki pengetahuan lebih baik dari pada mereka yang hanya lulusan sekolah dasar (SD/SMP), karena informasi yang di dapat dan pengalaman belajar lebih banyak sehingga ibu primigravida dengan lulusan menengah SMA berpengetahuan yang cukup.

Selain itu pekerjaan juga dapat melatarbelakangi ibu primigravida berpengetahuan cukup dalam memandikan bayi. Menurut Notoatmodjo (2012), seseorang yang mempunyai pekerjaan dengan waktu yang cukup padat pada umunya tidak mempunyai waktu luang. Hasil penelitian menunjukkan ibu primigravida yang tidak bekerja berpengetahuan cukup dalam memandikan bayi, karena ibu, lebih banyak waktu di rumah dan memiliki banyak waktu untuk mencari informasi tentang manfaat dan pentingnya cara memandikan bayi dengan benar.

Kemudian ibu primigravida berpengetahuan cukup dikarenakan ibu primigravida pernah mendapatkan informasi tentang memandikan bayi. Menurut Notoatmodjo (2014), pengetahuan adalah kesan atau penyampaian didalam pikiran manusia sebagai hasil panca pengindraan, penciuman, penglihatan, rasa dan raba. Hasil penelitian menunjukkan pengetahuan ibu primigravida cukup dikarenakan ibu mendapatkan informasi memandikan bayi baik mendapatkan informasi dari tenaga kesehatan, internet maupun dari orang lain, tetapi ibu hanya tahu saja dan tidak mendalami informasi yang didapat sehingga ibu hanya berpengetahuan cukup dalam memandikan bayi.

Tabel 2 pengetahuan setelah diberikan pendidikan memandikan bayi

\begin{tabular}{|c|c|c|c|}
\hline No. & Kriteria & Frekuensi (f) & Prosentase (\%) \\
\hline 1. & Baik & 15 & 88.2 \\
\hline 2. & Cukup & 0 & 0 \\
\hline 3. & Kurang & 2 & 11.8 \\
\hline & Jumlah & 17 & 100 \\
\hline
\end{tabular}

Tabel 2 menunjukkan hampir seluruhnya ibu primigravida setelah diberikan pendidikan memandikan bayi berpengetahuan baik yaitu 15 (88,2\%), ibu primigravida berpengetahuan cukup yaitu $0(0 \%)$, dan ibu primigravida berpengetahuan kurang menjadi 2 (11,8\%).

Setelah 50 menit ibu balita diberikan pendidikan memandikan bayi kemudian dilakukan Pengukuran pengetahuan dengan menggunakan alat bantu kuesioner berisi materi. Seperti yang dikutip dari Azwar (2013), pengukuran pengetahuan dapat dilakukan dengan menggunakan wawancara atau angket dengan alat bantu kuesioner berisi materi yang ingin diukur dari responden.

Jika dilihat dari pengetahuan setelah diberikan pendidikan hampir seluruhnya ibu primigravida mengalami peningkatan hal ini dikarenakan penyampaian informasi lebih mudah ke responden dikarenakan sebagian besar responden sudah memiliki 
tingkat pendidikan menengah. Informasi mengenai pentingnya memandikan bayi lebih mudah sampai kepada pasien karena pada umumnya semakin baik tingkat pendidikan seseorang maka semakin mudah pula penerimaan informasi yang didapat. Pengetahuan memandikan bayi setelah diberikan pendidikan didukung oleh sebagian besar responden berumur 20-35 tahun. Umur 20-35 tahun merupakan umur yang produktif dimana pada umur tersebut memiliki tingkat kematangan yang baik sehingga responden akan mempunyai cara pandang yang baik terhadap yang baru diketahui tentang memandikan bayi.

Hasil penelitian dari 8 ibu primigravida yang awalnya dalam pengetahuan cukup setelah diberikan pendidikan memandikan bayi pengetahuan ibu primigravida meningkat menjadi berpengetahuan baik, ini dikarenakan 8 ibu primigravida tersebut hanya membutuhkan pendidikan yang lebih mendalam dan mudah di pahami sehingga memiliki pemahaman yang lebih tentang memandikan bayi yang benar . Seperti yang dikutip Pepi Hapitria (2017), pemberian Pendidikan kesehatan untuk membantu individu, kelompok, dan masyarakat dalam meningkatkan kemampuan baik pengetahuan, sikap, maupun ketrampilan untuk mencapai hidup sehat secara optimal.

Penelitian ini didukung oleh hasil penelitian terdahulu, yaitu Virgia (2013) menunjukkan bahwa dari 14 responden yang mengalami perubahan cara dalam memandikan bayi sebanyak 12 orang $(85.71 \%)$ dan 1 orang $(7,14 \%)$ tidak mengalami perubahan, serta 1 orang $(7,14 \%)$ mengalami penurunan. Dari sini didapatkan hasil yang menunjukkan bahwa terdapat pengaruh antara pemberian penyuluhan memandikan bayi terhadap cara ibu memandikan bayi.

Ibu primigravida yang pengetahuan nya tidak meningkat dikarenakan bekerja sehingga tidak ada waktu untuk memahami pendidikan yang diberikan secara maksimal, selain itu pemberian pendidikan diberikan tidak secara langsung karena di lakukan pada saat pandemi COVID-19 dimana penerapan jarak social, penggunaan teknik pendidikan secara jarak jauh menjadi keharusan untuk efesiensi waktu, biaya, dan keamanan, oleh karena itu pendidikan dilakukan secara online, dan dalam peberian pendidikan tidak dilakukan pengawasan secara langsung, sehingga ibu primigravida kemungkinan tidak membaca dan memahami pendidikan yang diberikan. 
Tabel 3 perbedaan pengetahuan memandikan bayi sebelum dan setelah diberikan pendidikan memandikan bayi

\begin{tabular}{|c|c|c|c|c|c|c|c|c|}
\hline \multirow{3}{*}{$\begin{array}{l}\text { Pengetahuan } \\
\text { Sebelum } \\
\text { Pendidikan }\end{array}$} & \multicolumn{6}{|c|}{ Pengetahuan sesudah Pendidikan } & \multirow{2}{*}{\multicolumn{2}{|c|}{ Total }} \\
\hline & \multicolumn{2}{|c|}{ Baik } & \multicolumn{2}{|c|}{ Cukup } & \multicolumn{2}{|c|}{ Kurang } & & \\
\hline & $\mathbf{F}$ & $\%$ & $\mathbf{F}$ & $\%$ & $\mathbf{F}$ & $\%$ & $\mathbf{F}$ & $\%$ \\
\hline Baik & 5 & 29.4 & 0 & 0 & 0 & 0 & 5 & 29,4 \\
\hline Cukup & 8 & 47,1 & 0 & 0 & 0 & 0 & 8 & 47,1 \\
\hline Kurang & 2 & 11,8 & 0 & 0 & 2 & 11,8 & 4 & 23,5 \\
\hline Total & 15 & 88,2 & 0 & 0 & 2 & 11,8 & 17 & 100 \\
\hline & & & & I & 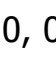 & & & \\
\hline
\end{tabular}

Tabel 3 bahwa hasil penelitian menunjukan pengetahuan ibu Primigravida yang awalnya memiliki pengetahuan cukup sebanyak $8(47,1 \%)$ dan berpengetahuan kurang sebanyak $2(23,1 \%)$, menjadi berpengetahuan baik sebanyak $15(88,2 \%)$ dan ibu primigravida yang memiliki pengetahuan kurang menjadi $2(11,8 \%)$ setelah diberikan pendidikan memandikan bayi.

Berdasarkan hasil analisa melalui uji Wilcoxon signed rank, didapatkan $\rho$ value: 0,003 dimana nilai $\rho<\mathrm{a} \mathrm{0,05}$ maka 0,003 $<0,05$ maka $\mathrm{H} 0$ ditolak dan $\mathrm{H} 1$ diterima yang berarti ada pengaruh pendidikan tentang pengetahuan memandikan bayi terhadap ibu primigravida.

Pendidikan kesehatan adalah usaha atau kegitan untuk membantu individu, kelompok, dan masyarakat dalam meningkatkan kemampuan baik pengetahuan, sikap, maupun ketrampilan untuk mencapai hidup sehat secara optimal (Pepi Hapitria, 2017).

Penelitian ini didukung oleh penelitian terdahulu, yaitu (Impartina, 2016) di Desa Trosono- Sekaran Kabupaten Lamogan menunjukkan , berdasarkan perhitungan menggunakan Wilcoxon sign rank test diperoleh nilai $Z=-3,419$, dimana $\mathrm{p}=0,01(p<0,05)$, maka Ho ditolak, artinya terdapat pengaruh pemberian motivasi terhadap kemampuan memandikan bayi.

Hasil penelitian Lukmawati (2017) di wilayah kerja Polindes Desa Sumberejo, kecamatan gampengrejo Kabupaten Kediri menunjukkan bahwa dari 14 responden, diuji dengan test wilcoxon didapatkan jenjang terkecil t hitung sebesar 3 dengan salah satu orang bernilai tetap, maka $n=13$ dengan taraf kesalahan $5 \%$ dan $T$ table $=17$, maka $3<17$. Artinya terdapat pengaruh antara pemberian penyuluhan memandikan bayi terhadap cara ibu dalam memandikan bayi.

Perubahan pengetahuan ibu primigravida tentang memandikan bayi terjadi karena Pemberian pendidikan yang diberikan melalui power point dan leaflet mudah di pamahi, serta memberikan informasi yang detail dan menarik yaitu tidak hanya 
informasi berisi tulisan tapi juga di berikan gambar. Sehingga responden lebih mudah memahami dan menyerap informasi yang pada akhirnya pengetahuan dalam memandikan bayi menjadi lebih mendalam dan mendapatkan pengertian yang lebih baik.

\section{KESIMPULAN DAN SARAN}

Kesimpulan dari penelitian ini adalah Ada pengaruh pengetahuan memandikan bayi usia 0-7 hari sebelum dan sesudah diberikan pendidikan pada ibu primigravida di wilayah kerja Puskesmas Pesantren 1 Kota Kediri tahun 2020. Dari hasil penelitian dapat disarankan untuk meningkatkan pengetahuan tentang memandikan bayi pada ibu primigravida dapat dilakukan pemberian pendidikan seperti penyuluhan dan pelatihan baik pada kelas ibu hamil maupun pada kegiatan yang lain.

\section{UCAPAN TERIMA KASIH}

Ucapan terimakasih kepada kepala Puskesmas Pesantren 1 Kota Kediri dan kepala kelurahan diwilayah kerja Puskesmas Pesantren 1 Kota Kediri yang bersedia dijadikan tempat penelitian. Dekan Fakultas Ilmu Kesehatan, serta Dosen pembimbing ibu Halimatus Saidah dan ibu Siswi Wulandari yang telah sabar dalam membimbing.

\section{DAFTAR PUSTAKA}

Alawiyah, dan A. (2018) 'Related factors with the way of mother babies in the working area of technical implemementation unit of the services, public health center bantarkalong sub district tasikmalaya district in 2017', Jurnal bidang ilmu kesehatan, 11(1), pp. 728-735.

Aprillia (2016) Hipnostetri: Rileks, Nyaman, dan Aman Saat Hamil. jakarta: Trans Media.

Arikunto, S. (2010) Prosedur Penelitian Pendekatan Praktik Edisi Revisi VI., Rineka Cipta.

Azwar, S. (2013) 'Sikap Manusia: Teori dan Pengukurannya', Sikap Manusia: Teori dan Pengukurannya. Yogyakarta: Pustaka Pelajar.

Best et al. (2019) 'The sexual health and wellbeing of vulnerable groups in Scotland':, International Journal of Environmental Research and Public Health, 9(May), pp. 14-18.

Bobak, L. (2015) Buku Ajar Keperawatan Maternitas. Jakarta: Egc.

Cahyono, Y. N. U. R. (2019) Pengaruh Pendidikan Kesehatan Dengan Audio Visual Terhadap Pengetahuan Memandikan Bayi Pada Ibu Hamil Di Desa Wirogunan Kecamatan Kartosuro. Universitas Muhammadiyah Surakarta.

Danis, M. (2013) Buku Saku Diagnosa Keperawatan. Jakarta: EGC.

Dewi, vivian nanny lia (2010) Asuhan neonatus bayi dan anak balita, Asuhan 
neonatus bayi dan anak balita.

Dian, A. (2014) Tumbuh Kembang dan Terapi Bermain pada Bayi dan Anak. Jakarta: Salemba Medika.

Elizabeth B, H. (2015) Psikologi Perkembangan. Jakarta: Erlangga.

Friedman, dkk (2014) Buku Ajar Keperawatan Keluarga. Jakarta: EGC.

Hidayah, et all (2015) 'Gambaran Pengetahuan dan Sikap Ibu Nifas Primipara Tentang Memandikan Bayi di Wilayah Kerja Puskesmas Sungai Lulut Banjarmasin', Jurnal Dinamika Kesehatan, 6(2), pp. 41-53.

Impartina (2016) 'Pendahuluan Asuhan masa nifas penting diberikan pada ibu dan bayi . Demikian halnya dengan masa neontus juga merupakan masa krisis dari kehidupan Kompetensi merupakan landasan dasar karakteristik orang dan berpikir, menyamakan situasi, dan lama. Memand', Rakernas Aipkema 2016, pp. 30-33.

Lestaluhu, V., Indrawan, I. W. A. and Andarini, S. (2018) 'Peningkatan Keterampilan Primigravida Dalam Merawat Bayi Dengan Penerapan Kombinasi Metode Buzz Group Dan Modelling', Journal Nursing Care and Biomolecular, 3(1), p. 27.

Lukmawati, D. (2017) 'Pengaruh penyuluhan memandikan bayi terhadap cara ibu dalam memandikan bayinya di desa sumberejo kecamatan gampengrejo kabupaten kediri', Juke, 1(2), pp. 64-70.

Ma'rufah (2019) Konseling Memandikan Bayi Terhadap Keterampilan Memandikan Bayi Usia 0-1 Bulan. Stikes Surya Mitra Husada.

Maryunani, A. (2014) IImu Kesehatan Anak dalam Kebidanan. Jakarta: Trans Info Media.

Notoatmodjo, S. (2010) Metodelogi Penelitian Kesehatan. Jakarta: Rineka Cipta.

Notoatmodjo, S. (2012) Promosi Kesehatan dan Perilaku Kesehatan. Jakarta: Rineka Cipta.

Notoatmodjo, S. (2014) Ilmu Perilaku Kesehatan. Jakarta: Rineka Cipta.

Nursalam (2013) Konsep dan Penerapan Metodologi Penelitian IImu Keperawatan. Jakarta: Salemba Medika.

Nursalam (2015) Konsep dan Penerapan Metodologi Penelitian IImu Keperawatan Edisi 2, Salemba Medika.

Pepi Hapitria, R. P. (2017) 'Efektifitas Pendidikan Kesehatan Melalui Multimedia dan Tatap Muka terhadap Pengetahuan dan Sikap Ibu Hamil tentang Asi dan Menyusui', Jurnal Care, 5 no 2, pp. 156-167.

Prasetyono (2013) Buku Pintar Pijat Bayi. Yogyakarta: Buku Biru. Priyono (2010) Merawat Bayi Tanpa Baby Sitter. Yogyakarta: Media Pressindo.

Rohmana dan Tat (2018) 'Merawat Bayi Dengan Status Kesehatan Bayi Post Perawatan Nicu Di Rsud', Chmk Nursing Scientific, 2(April), p. 10. Rukiyah (2012) Asuhan Neonatus Bayi dan Anak Balita. jakarta: Trans Info Medika. 
Jurnal Kesehatan Mahasiswa UNIK. Vol. 2, No. 1, Oktober 2020

P-ISSN: 2714-5409, E-ISSN: 2686-5300

Siswanto, H. (2016) Pendidikan Kesehatan Anak Usia Dini. Yogyakarta: Pustaka Rihama.

Sugiyanto, E. P. and Prasetyo, C. H. (2018) 'Hubungan Tingkat Kemampuan Dalam Merawat Diri Dan Bayinya Dan Bayinya Terhadap Tingkat Kecemasan Ibu Primigravida Trimester Ke Tiga', Jurnal Ilmu Keperawatan Jiwa, 1(2), p. 83.

Sugiyono (2018) Metode penelitian pendidikan. Bandung: Alfabeta.

Varney, H. (2010) Buku Ajar Asuhan Kebidanan Edisi 4. Jakarta: EGC.

Virgia, V. (2013) 'Pengaruh Penyuluhan Memandikan Bayi Terhadap Cara Ibu Dalam Memandikan Bayi', Jurnal Keperawatan \& Kebidanan - Stikes Dian Husada Mojokerto, pp. 43-48.

Walsh, L. (2014) Buku Ajar Asuhan Komunitas. Jakarta: Jakarta. 